\title{
A INSERÇÃO DA PERSPECTIVA CIÊNCIA- TECNOLOGIA-SOCIEDADE NA FORMAÇÃO INICIAL DE PROFESSORES DE QUÍMICA
}

\author{
The insertion of the Science-Technology-Society perspective in the \\ initial formation of chemistry teachers
}

\author{
Sinara München (sinara.munchen@uffs.edu.br) \\ Universidade Federal da Fronteira Sul
}

\begin{abstract}
Resumo: Neste trabalho investigou-se a inserção da perspectiva Ciência-TecnologiaSociedade (CTS) na formação inicial de professores em um componente curricular de Prática de Ensino, com estudantes de Licenciatura em Química de uma Instituição da região Centro-Oeste do país. Os instrumentos usados para coleta de dados foram dois questionários e sequências didáticas (SD) elaboradas pelos participantes da pesquisa. A partir dos dados dos questionários indica-se que os licenciandos apresentaram um conhecimento incipiente sobre a abordagem CTS no ensino, pois alguns aspectos ainda reforçam visões simplistas da ciência e tecnologia. As SD construídas destacam aspectos como o uso de temas, a tentativa de retomada da questão social ao final da SD, a discussão de assuntos controversos e de problemáticas ambientais, e as fragilidades evidenciadas são a exemplificação, a abordagem marcadamente conceitual e disciplinar e a ausência da discussão de questões tecnológicas. A partir das análises das SD pode-se observar que essa experiência desafiou os licenciandos a pensarem uma organização de ensino a partir de outra perspectiva. Embora, com diversas limitações, entende-se que é necessário que os professores em formação tenham espaços de discussão e reflexão acerca de abordagens de caráter mais amplo, apoiadas em temas/problemas relacionados ao contexto, e que possam discutir os modelos de desenvolvimento científico e tecnológico.
\end{abstract}

Palavras-chave: formação inicial de professores; CTS; Ensino de Química.

Abstract: In this work it was investigated the insertion of the Science- TechnologySociety perspective (STS) in the initial formation of teachers in a curricular component of Teaching Practice, with students from a Bachelor Course in Chemistry from an Institution of the Central-West region of the country. The tools used for the data collection were two questionnaires and didactic sequences (DS) elaborated by who were taking part of the research. From the data of the questionnaire, it is indicated that the students have an incipient knowledge about the STS approach in teaching, because some aspects still reinforce simplistic view of Science and technology. The DS built it is highlighted some aspects as the use of themes, the attempt of retrieving the social issue by the end of the DS, the discussion of controversial subjects and environmental problems, and the weaknesses highlighted are the exemplification, the approach distinctively conceptual and disciplinary and the absence of discussing technological issues. Because from the DS analysis it was possible to observe that this experience 
challenged the students to think on a teaching organization from another perspective. Although with some limitation, it is understood that it is necessary that teachers in formation have some places of discussion and reflection about the approaches with a wider character based on themes/issues related to context, and that can discuss the patterns of scientific and technological development.

Keywords: initial formation of teachers; STS; Teaching of Chemistry.

\section{INTRODUÇÃO}

O domínio do conhecimento científico e tecnológico permite, em muitas situações, refletir sobre questões que nos afetam diretamente e cotidianamente, como a produção de alimentos, fontes de energia, sustentabilidade, qualidade das águas, influência de artigos tecnológicos, entre tantas outras. O movimento CiênciaTecnologia-Sociedade (CTS) que iniciou sem direcionamento específico para o contexto educacional, a partir da década de 70 se propôs a discutir a necessidade de inserir nos currículos de ciências aspectos relacionados às interações entre ciênciatecnologia-sociedade (PINHEIRO, SILVEIRA e BAZZO, 2009).

Nesse sentido, diversos movimentos levaram, em âmbito mundial, à elaboração de currículos de ciências que contemplassem características do movimento CTS. Embora, diversas décadas tenham passado desde então, o enfoque CTS no contexto educacional no Brasil ainda pode ser considerado um campo em emergência, visto que ao se olhar para o contexto escolar suas inserções ainda não se efetivaram nos currículos e/ou nas práticas docentes (STRIEDER, 2012).

As dimensões políticas e econômicas têm influência relevante, tanto no direcionamento de configurações curriculares para a Educação Básica e para o Ensino Superior, quanto em aspectos referentes às condições de trabalho e remuneração dos profissionais da educação. Para garantir que problemáticas que envolvam questões científico-tecnológicas façam parte ou sejam o eixo central no ensino de ciências, são necessários diversos fatores, no entanto, se destaca o potencial do espaço de formação de professores.

Para Martins (2002) os professores de ciências podem determinar a qualidade da educação científica em espaços formais, no entanto, alterações significativas como mudanças curriculares não dependem apenas da ação docente individual, mas de um 
conjunto de atores que fazem parte do sistema educacional. André (2010) destaca que não se pode reforçar a compreensão simplista de que o professor é o principal e único responsável pelo desempenho da educação. Segundo a autora as pesquisas em educação mudaram seu foco para o professor, o que tirou a atenção dos cursos de formação inicial, que contabilizavam somente $18 \%$ das pesquisas em educação no ano de 2007. Esta constatação traz preocupação, pois há muitos aspectos a serem investigados na formação docente para o enfrentamento dos diversos desafios educacionais do século XXI.

Apesar das diversas pesquisas relacionadas à CTS no ensino de ciências, algumas das quais remetem à importância da inserção de estudos sobre CiênciaTecnologia-Sociedade e suas inter-relações na formação de professores de Ciências (PINHEIRO, SILVEIRA e BAZZO, 2007), estes ainda não se estabeleceram no contexto educacional e formativo como prática que faça parte desses processos. Nesse sentido, o espaço da formação inicial como lugar privilegiado para pensar, discutir e elaborar práticas pedagógicas pautadas em questões contemporâneas vinculadas à ciência e tecnologia, se coloca como potencial para esta pesquisa.

Ao considerar a importância do enfoque Ciência-Tecnologia-Sociedade em processos formativos de professores, este trabalho buscou identificar alguns aspectos a partir da inserção desse enfoque na formação inicial de professores de Química, visando elencar suas limitações e possibilidades. Nesse sentido, a pesquisa investigou o processo de inserção do enfoque CTS na formação inicial de professores de Química em um componente curricular de prática de ensino, a partir da aproximação com o movimento CTS, o enfoque CTS no ensino e a construção de sequências didáticas direcionadas ao Ensino Médio.

\section{A PERSPECTIVA CIÊNCIA-TECNOLOGIA-SOCIEDADE NO CONTEXTO EDUCACIONAL}

A inserção do enfoque Ciência-Tecnologia-Sociedade (CTS) no contexto educativo iniciou na década de 70, com a elaboração de novos currículos para o ensino de ciências que incluíam conteúdos de CTS, o que no Brasil, ocorre a partir da década de 80, no entanto, as pesquisas referentes a cursos de ciências com ênfase em CTS são 
desenvolvidas somente na década de 90 (PINHEIRO, SILVEIRA e BAZZO, 2009; SANTOS, 2007).

Santos (2007, p. 03) ressalta que "aspectos curriculares relativos a cursos com ênfases em CTS sempre estiveram presentes implicitamente em recomendações curriculares de ensino de ciências, na medida em que o propósito desse ensino sempre esteve voltado para a cidadania". Com a publicação dos Parâmetros Curriculares Nacionais (PCN) (BRASIL, 1998) aparece, então, a primeira recomendação explícita de inserção de CTS na organização curricular nacional, que permanece nas diversas versões dos PCN do ensino fundamental e médio (SANTOS, 2007).

Os objetivos do ensino a partir de uma abordagem CTS se caracterizam pelo entendimento da interdependência entre Ciência-Tecnologia-Sociedade visando à capacidade de tomada de decisão para uma participação ativa na sociedade democrática (SANTOS e SCHNETZLER, 2003), visto que o meio social contemporâneo é indissociável de aspectos científico-tecnológicos. Para Santos e Schnetzler (2003, p. 64) a educação CTS se caracteriza como "organização conceitual centrada em temas sociais, pelo desenvolvimento de atitudes de julgamento, por uma concepção de ciência voltada para o interesse social, visando compreender as implicações sociais do conhecimento científico".

No mesmo sentido, Santos e Mortimer (2000) apontam alguns princípios das propostas CTS para o contexto educativo: a formação de valores e atitudes em oposição à memorização de conceitos e a preparação para o vestibular; a abordagem por temas ao invés dos programas desvinculados das vivências dos alunos; e um ensino que coloque o aluno em uma posição ativa frente ao processo de ensino e aprendizagem. Os objetivos da perspectiva CTS no ensino se relacionam ao desenvolvimento de valores como a solidariedade, fraternidade, consciência do compromisso social, reciprocidade, respeito ao próximo e generosidade, estes vinculados aos interesses coletivos e que se relacionam às necessidades humanas, contrapondo-se ao valor econômico como majoritário/sobreposto aos demais (SANTOS, 2007).

O entendimento das inter-relações CTS na perspectiva da formação de um cidadão, constituído por valores, infere em abordagens contextualizadas e interdisciplinares, que possibilitem situar a ciência e a tecnologia no contexto social, político, econômico, cultural, e valorizem os conhecimentos de disciplinas para além 
das ciências naturais e exatas, visto que os temas necessitam de conhecimentos de diversas áreas para uma compreensão ampliada. Há então a necessidade de compreender a contextualização como algo mais amplo que a inserção de exemplos de aplicações da ciência para contemplar questões de relevância do contexto em que os estudantes vivem.

Auler (2002) indica que ao discutir currículos CTS, consequentemente, estão em discussão concepções de cidadania, de modelos de sociedade e de desenvolvimento tecnológico. Os currículos e/ou as abordagens de ensino fundamentadas na perspectiva CTS devem ter clareza a que "tipo de cidadania" está a servir, visto que podem intitularse dessa perspectiva, mas não seguir seus princípios.

Apesar de se observar em diversas pesquisas (STRIEDER, 2012; FREITAS e GHEDIN, 2015) um crescimento em trabalhos vinculados ao enfoque CTS e, uma porcentagem significativa destes estarem direcionados a inserções de propostas em sala de aula, são considerações comuns das pesquisas que há uma polissemia relacionada a este enfoque. Strieder (2012) destaca que embora indiquem partir dos pressupostos do movimento CTS nem todos os trabalhos conseguem articulá-los na prática docente.

Algumas limitações apontadas por pesquisadores para implementação da perspectiva CTS no Brasil são a falta de materiais didáticos, as concepções dos professores e a ausência da participação popular nas decisões (PINHEIRO et al., 2009). Auler (2011) ressalta a questão da ausência de uma cultura de participação nacional que influencia diretamente na inserção e desenvolvimento do movimento CTS no contexto educacional.

Para Santos e Mortimer (2000) é necessária uma modificação substancial na prática e nas concepções pedagógicas para que as inter-relações CTS sejam contempladas nos espaços educacionais. Esse entendimento é corroborado por Zanon et al (2010) ao entender que as concepções dos docentes sobre a sua formação e a prática profissional influenciam a formação de um professor qualificado, pois alterações curriculares nos cursos de formação de professores não garantem isoladamente a exigência da constituição do docente.

Muitas pesquisas têm investigado a perspectiva CTS na formação de professores de Ciências nas últimas décadas a partir de diversas abordagens na tentativa de reconhecer encaminhamentos possíveis a essa demanda (AULER, 2002; AULER e 
DELIZOICOV, 2006; MARTINS, 2002; TRIVELATO, 1993; FIRME 2007; CASSIANI e LINSINGEN, 2009). As produções brasileiras em CTS tem indicado algumas tendências e direcionamentos, entre as quais é apontada a necessidade de inserir e investigar práticas CTS na formação inicial de professores.

Ao considerar que esta pesquisa se concentra no processo de formação inicial de professores foi proposta uma intervenção em um curso de Licenciatura em Química como um caminho para a reflexão sobre as limitações e as potencialidades do enfoque CTS ao Ensino de Ciências, que visa, sobretudo, a formação de professores com um olhar menos reducionista sobre as interações entre o conhecimento científico e tecnológico e os espaços e vivências sociais, assim como, para as potencialidades dos espaços educativos enquanto formadores de indivíduos participativos.

\section{ABORDAGEM METODOLÓGICA}

Esta pesquisa está embasada a partir de uma abordagem predominantemente qualitativa, que conforme Lüdke e André (2013) se caracteriza pelo ambiente natural (o mundo real) como fonte para a coleta de dados e a interação entre sujeito, pesquisador e objeto. Os instrumentos usados para a coleta de dados da pesquisa foram questionários e sequências didáticas. Foram construídos e aplicados dois questionários, um com perguntas abertas, e o outro, o $\operatorname{VOSTS}^{1}$, que se baseia em perguntas de múltipla escolha. Os questionários visavam investigar as compreensões sobre CTS.

A pesquisa documental se configura a partir de documentos, neste caso categorizados como fontes primárias, os quais foram as sequências didáticas (SD) elaboradas pelos licenciandos durante o desenvolvimento da pesquisa. A análise das SD poderá fornecer indícios sobre as compreensões construídas acerca do enfoque CTS e sua organização visando o espaço de sala de aula.

O grupo de participantes da pesquisa foi constituído por acadêmicos/as de um curso de Química com habilitação em Licenciatura e Bacharelado, diurno e em turno integral, de uma instituição pública de ensino da região Centro-Oeste. Os sujeitos da

\footnotetext{
${ }^{1} \mathrm{O}$ questionário Views on Science Technology and Society (VOSTS) é de autoria de Aikenhead et al (1989), e é utilizado em todo o mundo na investigação de concepções sobre ciência-tecnologia-sociedade e suas interações. O questionário original é formado por 114 itens, com frases assertivas.
} 
pesquisa foram 28 acadêmicos/as, dos quais 25 cursavam o $6^{\circ}$ semestre, e os demais estavam em semestres posteriores, todos entre o terceiro e quarto ano de graduação.

Para preservar a identidade dos sujeitos da pesquisa, estes serão mencionados a partir de um código composto por uma letra e um número, a saber, L1, L2, L3, e assim sucessivamente. Todos os estudantes que aceitaram participar da pesquisa assinaram o Termo de Consentimento Livre e Esclarecido.

As atividades formativas foram desenvolvidas em um componente curricular integrante da carga horária das práticas de ensino, aliando as compreensões sobre a perspectiva CTS à elaboração de um planejamento didático para a disciplina de Química do Ensino Médio. As atividades ocorreram durante 20 horas-aula, distribuídas em cinco encontros. Como um dos elementos dessa investigação, optou-se pelo estudo de um tema, o Jeans, como forma de aproximar e inserir diversas discussões acerca das interações entre Ciência, Tecnologia e Sociedade nas atividades propostas. A escolha pelo tema se deu por diversos fatores, entre eles a massiva presença desse item do vestuário na sociedade contemporânea, a pouca exploração do mesmo em publicações referentes ao ensino de ciências, as potencialidades frente ao Ensino de Química e a riqueza de discussões perante as relações CTS.

As SD foram analisadas a partir de um instrumento construído por Silva e Marcondes (2015), que se caracteriza nas seguintes etapas de análise para as unidades/sequências didáticas no enfoque CTS:

1. Situação-problema ou tema - identificado pelo título dado à unidade didática e atividade de abertura. Verificou-se a presença de um tema ou ocorrência de uma problematização;

2. Visão geral do problema ou tema - parte do instrumento que permite a análise das informações que explicitam o tema ou problema abordado, e as relações com aspectos das áreas CTS que a unidade possa trazer em sua estrutura;

3. Conhecimento específico da Química - procurou-se verificar se o conhecimento da química tratado na unidade do professor estabelece relação forte, média ou fraca com o tema ou problema;

4. Nova leitura do tema ou problema - analisou-se se a unidade didática retoma alguma discussão sobre o tema ou problema ou não, apresenta nova situação que amplia os entendimentos sobre o problema ou, ainda, apresenta nova situação provocativa com vistas a resolver o problema (SILVA e MARCONDES, 2015, p. 68). 
As sequências didáticas são então organizadas em um esquema, de acordo com a Figura 1, que apresenta as etapas anteriormente citadas, com suas relações a aspectos que envolvem a Ciência, a Tecnologia e a Sociedade.

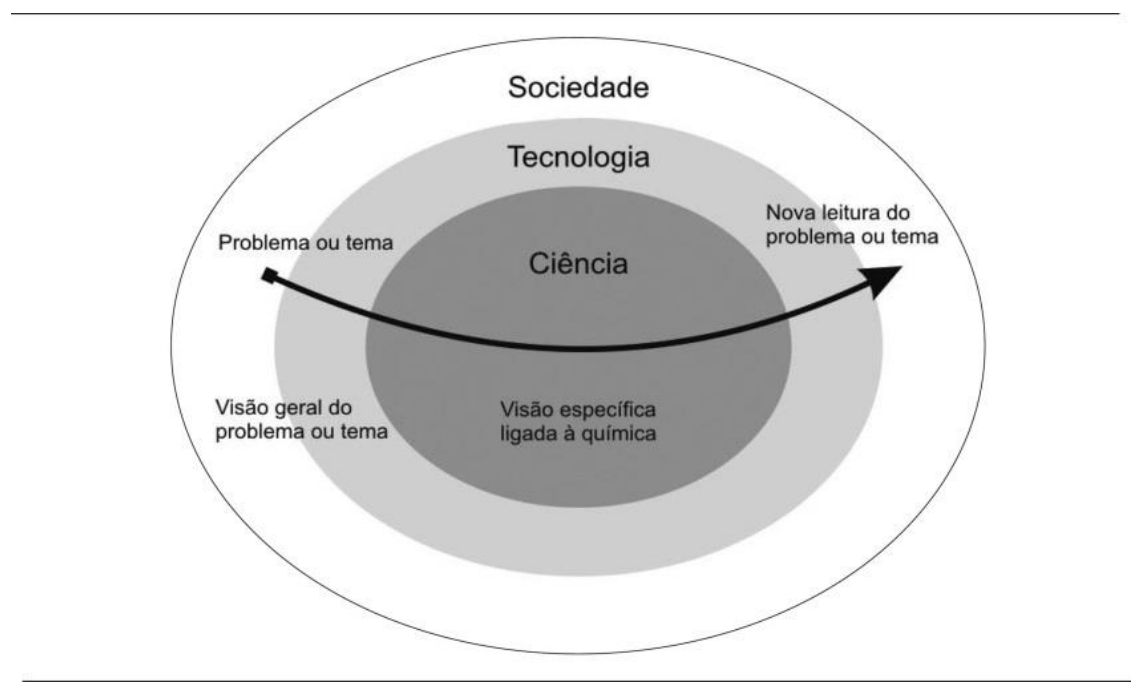

Figura 1 - Instrumento para análise das unidades didáticas. Fonte: Silva e Marcondes, 2015.

Este instrumento foi elaborado a partir de dois outros: a estrutura apontada por Aikenhead (1994) para o desenvolvimento de propostas CTS e o modelo estrutural proposto para elaboração de unidades didáticas contextualizadas de Marcondes e cols (2007). A estrutura de Aikenhead (1994) organiza a abordagem de um tema a partir de questões sociais que são relacionadas a tecnologias, técnicas e produtos, a partir dos quais é definido o conteúdo da ciência a ser abordado. Nessa perspectiva, retorna-se a tecnologia e ao final a questão social é retomada.

\section{A INSERÇÃO DO ENFOQUE CTS NA FORMAÇÃO INICIAL DE PROFESSORES DE QUÍMICA}

No primeiro questionário foi possível observar que a maior parte dos entendimentos dos licenciandos sobre a perspectiva CTS no ensino se baseava em exemplificação de impactos gerados pela ciência e tecnologia na sociedade, a inserção de aspectos do cotidiano, a contextualização, e a tomada de decisão limitada a questões relativas a consumo, por exemplo. Apenas alguns destacam a abordagem interdisciplinar, a formação de um cidadão crítico e a tomada de decisão voltada a 
questões coletivas. O estudante L7 diz que "A proposta CTS ou CTSA visa contextualizar o conceito química ou científico na realidade do aluno, assim transformando-o em um cidadão conhecedor e atuante no meio em que vive. Um aluno educado segundo esta compreensão tem capacidade, por exemplo, de escolher os seus produtos não pelo preço ou marca, mas sim por componentes e princípios ativos".

De modo geral, são encontradas nas respostas dos licenciandos diversas compreensões limitadas acerca do entendimento das interações CTS, embora todos indiquem conhecer a abordagem CTS no ensino. A ausência de entendimento da ciência como construção social e visões reducionistas sobre ciência e tecnologia em licenciandos que estão em etapas finais de sua formação ressalta que há poucas discussões ou intervenções relacionadas a esses aspectos, ou as abordagens não estão levando a um olhar mais amplo sobre a produção do conhecimento científico e tecnológico, perpetuando compreensões simplistas, que irão refletir no modo de construção de sua prática docente (ACEVEDO DÍAZ, 1996). Para o autor, o professor não irá ensinar aquilo que não conhece, portanto, para trabalhar com as relações CTS é necessário para que possa compreender as suas inter-relações e as implicações envolvidas com esta abordagem no ensino.

O reforço de visões de ciência e tecnologia com caráter de neutralidade, muitas vezes instituídos pelas configurações curriculares, pelo discurso e/ou prática docente dos formadores, potencializa entendimentos pouco adequados acerca da ciênciatecnologia-sociedade e suas interações. Essas problemáticas, vinculadas a concepções simplistas dos licenciandos, estão relacionadas a diversos fatores, entre eles a configuração curricular das licenciaturas e as concepções dos formadores (BISPOFILHO et al, 2013). Os autores apontam como relevante a inclusão de temas CTS nos currículos de graduação e nos processos formativos dos formadores para possibilitar a superação de muitas compreensões limitadas sobre ciência e tecnologia.

Com a análise do questionário VOSTS foi possível indicar que as compreensões dos licenciandos participantes da pesquisa encontram-se dispersas nas três categorias, (Simplista, Plausível, Realista) concentrando-se na categoria Plausível. As respostas apresentadas dentro desta categoria apresentam tanto compreensões adequadas quanto entendimentos pouco complexificados das inter-relações CTS. Esses resultados podem sugerir que as visões simplistas sobre ciência e tecnologia em alguns pontos como a 
participação social nas tomadas de decisões sobre questões da ciência e tecnologia vem sendo problematizadas, enquanto aspectos como a responsabilidade social dos cientistas sobre suas pesquisas necessitariam de maiores discussões nos espaços formativos.

A questão 6 direcionava-se ao entendimento da responsabilidade social dos cientistas e técnicos com os efeitos de suas pesquisas, e dezenove licenciandos apresentaram respostas que indicam compreensões simplistas. Quinze escolheram a assertiva C “Os cientistas estão preocupados com todos os efeitos de suas experiências, porque o objetivo da Ciência é tornar o nosso mundo um lugar melhor para vivermos. Sendo assim, a preocupação em compreender as descobertas da Ciência é uma parte natural de sua realização", apontada como compreensão simplista.

A questão 8 tinha como enunciado "A Ciência e a Tecnologia podem dar grandes contribuições à resolução de problemas, tais como: pobreza, crime, desemprego, doenças, ameaça de guerra nuclear e excessos de população. Sua posição, basicamente, é:". As respostas foram categorizadas majoritariamente como realistas e plausíveis, e a opção C "A Ciência e a Tecnologia podem contribuir para resolver certos problemas sociais, mas podem também estar na origem de muitos outros." foi assinalada por 11 licenciandos, a qual apresenta um entendimento menos ingênuo sobre as relações entre CTS.

Acevedo Díaz (1996) aponta que a formação inicial poderá propiciar algumas orientações sobre as inter-relações CTS, no entanto, muitos dos enfrentamentos ocorrerão no cotidiano da prática docente, o que indica a necessidade de um processo formativo contínuo, para que as limitações possam ser refletidas, discutidas e, se possível, superadas. Os resultados encontrados contribuem para refletir de que maneira alguns destes aspectos podem ser discutidos na formação inicial e de que forma pode-se inserir questões CTS na formação de professores.

Nesse sentido, a proposta de elaborar um planejamento didático a partir do enfoque CTS foi a opção da pesquisa. A elaboração das sequências didáticas (SD), que para Zabala (1998, p.18) "são um conjunto de atividades ordenadas, estruturadas e articuladas para a realização de certos objetivos educacionais, que têm um princípio e um fim conhecido tanto pelos professores como pelos alunos", ocorreu em grupos (de dois a quatro integrantes). As onze sequências didáticas elaboradas estão especificadas no Quadro 4, com seus respectivos temas e conteúdos conceituais de química. 
Em relação à abrangência dos temas, todas SD apresentam um caráter universal, possibilitando seu desenvolvimento em diversos contextos escolares. Algumas trazem questões próximas ao contexto dos licenciandos, pois a região se destaca pelas áreas de agricultura extensiva, para produção de grãos, açúcar e etanol. Ao considerar a articulação entre o tema e o conteúdo, das onze SD, oito apresentam de forma predominante características de uma abordagem temática $(1,2,4,6,7,8,9,10)$ e duas de abordagem caracterizada como conceitual (3 e 11). A SD 5 não apresentou um conteúdo/conceito a ser desenvolvido, indicando que o professor deveria defini-lo diante da situação de ensino, devido a essa característica esta SD foi desconsiderada para análise visto que não permitiu estabelecer as possíveis relações entre aspectos CTS. Um dos licenciandos, identificado como L12, não participou da elaboração da sequência didática, por isso não consta no Quadro 1.

Quadro 1 - Os temas e conteúdos das SD elaboradas pelos licenciandos em química.

\begin{tabular}{|c|c|c|c|}
\hline Identificação & Título/Tema & Conteúdo (s) Químico (s) & Licenciandos \\
\hline 1 & Agrotóxicos & Funções orgânicas & L9 e L26 \\
\hline 2 & Agrotóxicos & $\begin{array}{l}\text { Agente laranja (formado por ácido } \\
2,4 \text {-diclorofenoxiacético } \quad(2,4-\mathrm{D}) \text { e } \\
\text { ácido 2,4,5-triclorofenoxiacético } \\
(2,4,5-\mathrm{T}) \text { e pentaclorofenol) }\end{array}$ & L17, L24 e L25 \\
\hline 3 & $\begin{array}{l}\text { Meio ambiente uma } \\
\text { proposta com o tema } \\
\text { acidez e basicidade }\end{array}$ & Ácidos e Bases & L3, L19 e L20 \\
\hline 4 & Açúcar & Estrutura e funções orgânicas & L6 e L22 \\
\hline 5 & Cosméticos & Não definido pelos autores & L10, L16 e L28 \\
\hline 6 & Biogás & Entalpia de reação química & L5 e L11 \\
\hline 7 & Combustíveis & Função orgânica álcool & L4 e L27 \\
\hline 8 & Mudanças Climáticas & Cálculo estequiométrico & L2 e L18 \\
\hline 9 & $\begin{array}{l}\text { Alimentos } \\
\text { industrializados }\end{array}$ & Estrutura molecular & L8, L14 e L23 \\
\hline 10 & Lei Seca & Reações de oxirredução & L1, L7 e L21 \\
\hline 11 & Pilhas & Eletroquímica & L13 e L15 \\
\hline
\end{tabular}

Fonte: elaborado pela autora. 
As 10 sequências didáticas foram analisadas a partir dos parâmetros elencados pelas etapas já descritas. Uma das SD que trata dos agrotóxicos, a SD 1, intitulada "Agrotóxico e meio ambiente uma abordagem CTS de bioinseticidas no Ensino de Química”, propõe uma produção textual sobre as atividades da família no campo relacionadas com o meio ambiente e os agrotóxicos, a partir da qual os alunos deverão indicar um posicionamento sobre o uso dessas substâncias nas plantações. Segundo os autores, a SD seria desenvolvida em escolas do campo. A atividade inicial se caracteriza como um levantamento das compreensões dos alunos sobre o tema, podendo desdobrarse em uma problematização sobre o uso de agrotóxicos no cultivo de plantas.

A SD traz diversos momentos relacionados a aspectos sociais e ambientais sobre o tema, especialmente a partir de uma fotonovela e um vídeo que retratam casos de intoxicação por agrotóxicos. Aspectos científicos são ressaltados em uma aula expositiva, com a composição, classes toxicológicas e contaminação de alimentos por agrotóxicos, e a partir da experimentação, que visa à formulação de bioinseticidas. Com as estruturas moleculares dos princípios ativos dos bioinseticidas, os alunos deverão identificar os elementos químicos, os tipos de ligações e as funções orgânicas. Nenhum item foi explorado em relação a aspectos tecnológicos. O fechamento da SD se dá com uma visita a uma fazenda que produz café de forma agroecológica, atividade que pode ser considerada como uma nova visão para a problemática dos agrotóxicos, conforme figura 2, visto que visa proporcionar aos estudantes a compreensão sobre outras práticas para a produção de alimentos, sem o uso de agrotóxicos.

De modo geral a SD1, contempla de forma satisfatória a abordagem social do tema e os aspectos conceituais da Química, assim como propõe uma atividade que promove uma nova visão sobre o tema, no entanto não explora discussões de caráter tecnológico, que poderiam potencializar as compreensões sobre agrotóxicos. Nesse direcionamento podem ser destacados diversos elementos sobre a não neutralidade da atividade científica, considerando o desenvolvimento dos agrotóxicos que serviu para potencializar a produção de alimentos, no entanto, há diversos efeitos e impactos relacionados ao seu uso, como doenças em seres humanos, contaminação de alimentos, recursos hídricos e da fauna e flora. O entendimento de que "não existem alternativas ao uso destes produtos na lavoura, afirmação determinista controlada pela indústria química através dos seus diversos meios de comunicação" (PERES e ROZEMBERG, 
2003, p.334) reafirma a compreensão fatalista de que os agrotóxicos, mesmo com alguns impactos conhecidos, não têm seu uso questionado.

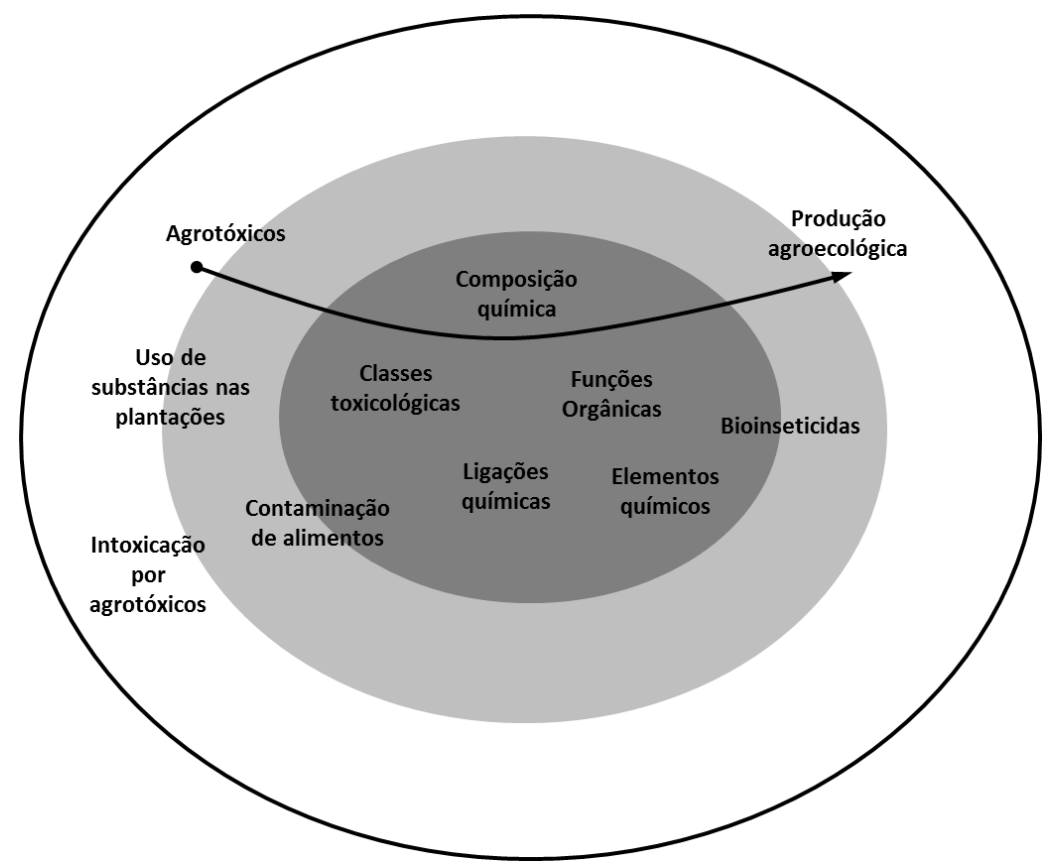

Figura 2 - Estrutura da sequência didática 1. (elaborado pela autora).

As discussões ficam restritas majoritariamente ao pós-produção, como na SD 7 com a escolha entre o combustível com menor impacto ambiental. A SD 1 que traz alternativas a agricultura convencional indica um outro modelo para o cultivo de alimentos, no entanto essa discussão não é aprofundada.

Além de uma configuração curricular baseada em temas sociais, a perspectiva CTS objetiva a democratização das decisões relacionadas a problemas contemporâneos, especialmente vinculados ao desenvolvimento científico-tecnológico, esse último não contemplado nas SD analisadas. Para alcançar o entendimento das interações CTS a partir de uma perspectiva ampliada de participação alguns pesquisadores (ROSA, 2014; SANTOS, 2016) apontam para a aproximação dos referenciais de Freire e do PLACTS visando à superação de um entendimento restrito a avaliação dos impactos da ciência e tecnologia na sociedade.

Rosa e Strieder (2018) indicam que a educação CTS está alinhada à pressupostos democráticos, efetuada a partir dos temais sociais, no entanto nem todas as proposições intituladas CTS se pautam nessa perspectiva. As autoras destacam que, estas propostas 
apontam problemáticas pensadas e resolvidas a partir do conhecimento científicotecnológico de forma praticamente exclusiva, o que se distancia de uma participação ampliada mesmo em situações de sala de aula.

Esses aspectos se relacionam as SD analisadas, visto que muitas das propostas não retornavam à questão social. Quem escolhe e quais são os valores que permeiam a produção do conhecimento científico-tecnológico são aspectos que devem fazer parte das discussões relativas às interações CTS. Uma participação ampliada se relaciona a decisões que antecedem o consumo ou o pós-produção, e as propostas educacionais orientadas na perspectiva CTS, a partir de sua aproximação com referenciais freireanos, podem propiciar a construção de uma cultura de participação social, buscando democratizar os processos decisórios para além das escolhas vinculadas ao consumo (SANTOS, 2016).

Com essa dimensão explícita é possível considerar que alguns pontos importantes da abordagem CTS não foram contemplados pelos licenciandos no planejamento das sequências didáticas. Isso remete as limitações que se justificam pela brevidade e pelas escolhas das discussões nos momentos formativos destinados ao estudo da abordagem CTS no ensino, no entanto, também se relaciona com a formação de uma forma geral, visto que o entendimento das consequências do desenvolvimento científico e tecnológico não deve estar restrito ao estudo dessa abordagem, mas sim perpassar discussões de diversos componentes curriculares ao longo da formação. Devido à pouca expressividade desses questionamentos do modelo de desenvolvimento nas SD pode-se inferir que essas questões são pouco problematizadas e discutidas nos espaços de formação desses licenciandos.

Esses resultados se relacionam aos encontrados por Rosa (2014) que, ao pesquisar práticas educativas em CTS, identificou um silenciamento relativo à presença de valores na concepção e produção da ciência e tecnologia, destacando que a sociedade realiza apenas avaliação crítica dos impactos causados pelo uso da CT. A autora defende que, a partir desses silenciamentos, o maior desafio seja traduzir a compreensão crítica de CTS relacionada à perspectiva ampliada para as práticas educativas.

Ao afirmar que apenas um componente curricular não é suficiente para abarcar a ampla gama de discussões referentes a essa questão, indico que as discussões relacionadas ao modelo de desenvolvimento científico e tecnológico devem perpassar 
diversos componentes curriculares, especialmente de um curso de Licenciatura em Química. Estas relações precisam ser um tema em debate no âmbito universitário, visto que é neste espaço que ocorre a profissionalização do futuro professor, no entanto, discussões mais amplas necessitam estar articuladas a um estudo da abordagem das relações Ciência-Tecnologia-Sociedade para que sejam problematizadas abordagens de ensino que se referenciem nessa perspectiva.

\section{CONSIDERAÇÕES FINAIS}

O que considero como avanço na formação inicial a partir de minha experiência docente e de pesquisa é a inserção da abordagem CTS como possibilidade desenvolvida com os licenciandos. Embora, com diversas limitações, entendo que é necessário que os professores em formação se apropriem de abordagens que visam superar um ensino limitado por conceitos, e que isso não seja restrito a um componente curricular ou a escolha do professor formador, mas que a formação de modo geral possibilite espaços de discussão e reflexão acerca destas abordagens. Martins (2002) aponta que um ensino com orientação CTS só será realidade no contexto escolar quando também estiver como parte do ensino superior.

Ao partir desses questionamentos é que podem ser pensadas algumas práticas que interliguem os cursos de licenciatura nas instituições de formação, como a integração com licenciaturas de várias áreas em um componente de prática de ensino que trabalhasse em uma abordagem temática. Outra possibilidade seria articulação entre os estágios de diversos cursos de licenciatura, o que poderia promover interações entre estudantes que estejam vivenciando a etapa de estágio.

São algumas sinalizações que poderiam integrar as áreas de formação já no período de formação inicial, pois articularia formadores e licenciandos que futuramente, em situação profissional teriam alguma vivência de trabalho coletivo que pudesse embasar práticas no contexto escolar, além de promover experiências nessa perspectiva no desenvolvimento dos estágios supervisionados.

Sousa e Brito (2015) sugerem que a formação inicial é um espaço propício para fomentar discussões acerca dos entendimentos sobre as relações CTS a partir de um debate orientado, para que durante este período formativo os futuros professores possam 
problematizar suas compreensões sobre CTS e sejam minimizados modelos ingênuos e simplistas acerca das interações ciência-tecnologia-sociedade nos espaços de sala de aula.

Nesse sentido, retomo a experiência desta pesquisa, pois um componente de prática de ensino que integrasse as licenciaturas com direcionamento de estudo a perspectivas interdisciplinares como CTS, entre outras, certamente teria contribuições mais enriquecedoras na formação. Considerando os questionamentos e possíveis práticas que emergiram com a pesquisa ressalto que os espaços para que a formação possa caminhar no sentido de discussões mais amplas precisam ser criados também nas instituições que promovem essa formação, articulada ao contexto escolar, o que pode se dar a partir dos componentes curriculares e de projetos de pesquisa e extensão.

\section{REFERÊNCIAS}

ACEVEDO DIAZ, J.A. La Formación del Profesorado de Enseñanza Secundaria para la Educación CTS. Una cuestión problemática. 1996. Revista interuniversitaria de formación del profesorado, n. 26, 1996. Disponível em: http://www.oei.es/salactsi/acevedo9.htm. Acesso em: 05 jun. 2019.

AIKENHEAD, G. S. The social contract of science: implications for teaching science In: SOLOMON, J.; AIKENHEAD, G. S. (Org.). STS education-international perspectives on reform. New York: Teachers College Press, 1994. p. 11-20.

ANDRÉ, M. Formação de professores: a constituição de um campo de estudos. Revista Educação, Porto Alegre, v. 33, n. 3, p. 174-181, set./dez. 2010. Disponível em: http://revistaseletronicas.pucrs.br/ojs/index.php/faced/article/view/8075/5719 Acesso em: 30 maio 2019.

AULER, D. Interações entre ciência-tecnologia-sociedade no contexto da formação de professores de ciências. 2002. 258 p. Tese (Doutorado em Educação Científica e Tecnológica). Universidade Federal de Santa Catarina, Florianópolis, 2002.

AULER, D. Novos caminhos para a educação CTS: ampliando a participação. IN: SANTOS, W. L. P.; AULER, D. (org.) CTS e educação científica: desafios, tendências e resultados de pesquisa. Brasília: Editora Universidade de Brasília, 2011.

AULER, D.; DELIZOICOV, D. Ciência-Tecnologia-Sociedade: relações estabelecidas por professores de ciências. Revista Electrónica de Enseñanza de las Ciencias Vol. 5 $\mathrm{N}^{\mathrm{o}} 2$ 2, 2006. Disponível em:http://reec.uvigo.es/volumenes/volumen5/ART8_Vol5_N2.pdf Acesso em: 20 maio 2019. 
BRASIL. Ministério da Educação. Secretaria de Educação Fundamental. Parâmetros Curriculares Nacionais: Ciências Naturais. Brasília: MEC, 1999.

CASSIANI, S.; VON LINSINGEN, I. Formação inicial de professores de Ciências: perspectiva discursiva na educação CTS. Educar em Revista (Impresso), p. 127-147, 2009. Disponível em: http://www.scielo.br/pdf/er/n34/08.pdf Acesso em: 25 jun. 2019.

FIRME, R.A. A implementação de uma abordagem CTS no ensino da química: um olhar sobre a prática pedagógica. 2007. 204 p. Dissertação (Mestrado em Ensino de Ciências). Universidade Federal Rural de Pernambuco. Disponível em: http://200.17.137.108/tde_busca/arquivo.php?codArquivo=1204 Acesso em: 05 jul. 2019.

FRISON, M. D. A produção de saberes docentes articulada à formação inicial de professores de química: implicações teórico-práticas na escola de nível médio. 2012. 311 p. Tese (Doutorado em Educação em Ciências). Universidade Federal do Rio Grande do Sul, Porto Alegre, 2012. Disponível em: https://www.lume.ufrgs.br/bitstream/handle/10183/61253/000864942.pdf?sequence=1. Acesso em: 10 jul. 2019.

LÜDKE, M.; ANDRÉ, M. E. D. A. Pesquisa em Educação: Abordagens Qualitativas. São Paulo: EPU, 2013. 99 p.

MARCONDES, M. E. R. et al. Oficinas temáticas no ensino público visando a formação continuada de professores. São Paulo: Imprensa Oficial do Estado de São Paulo, 2007.

MARTINS, I. P. Problemas e perspectivas sobre a integração CTS no sistema educativo português. Revista Electrónica de Enseñanza de las Ciencias, Vol. 1, № 1, p. 28-39, 2002. Disponível em:

http://www.saum.uvigo.es/reec/volumenes/volumen1/Numero1/Art2.pdf. Acesso em: 04 jun. 2019.

PERES, F.; ROZEMBERG, B. É veneno ou é remédio? Os desafios da comunicação rural sobre agrotóxicos. In: PERES, Frederico; MOREIRA, Josino C. (Orgs.). É veneno ou é remédio? Agrotóxicos, saúde e ambiente. Rio de Janeiro: Editora FIOCRUZ, 2003, p.329-348.

PINHEIRO, N. A. M.; SILVEIRA, R. M. C. F.; BAZZO, W. A. O contexto científicotecnológico e social acerca de uma abordagem crítico-reflexiva: perspectiva e enfoque. Revista Iberoamericana de Educación, n. 49, v. 01, p. 01-14, mar. 2009. Disponível em: http://www.rieoei.org/deloslectores/2846Maciel.pdf. Acesso em: 08 jun. 2019.

PINHEIRO, N.A.M.; SILVEIRA, R.M. C.F.; BAZZO, W.A. Ciência, Tecnologia e Sociedade: a relevância do enfoque CTS para o contexto do Ensino Médio. Ciência \& Educação, vol.13, n.1, pp.71-84, 2007. ISSN 1516-7313. Disponível em: http://www.scielo.br/pdf/ciedu/v13n1/v13n1a05.pdf Acesso em: 20 jun. 2019. 
ROSA, S. E. Não Neutralidade da Ciência-Tecnologia: problematizando silenciamentos em práticas educativas relacionadas a CTS. 2014. 123 p. Dissertação (Mestrado em Educação) Universidade Federal de Santa Maria, Santa Maria, RS, 2014.

ROSA, S. E.; STRIEDER, R. B. Dimensões da democratização da ciência-tecnologia no âmbito da educação CTS. Revista Insignare Scientiae, v. 1, n. 2., 2018. Disponível em: https://periodicos.uffs.edu.br/index.php/RIS/article/view/8251/5646 Acesso em: 20 out. 2019.

SANTOS, R.A. dos. Busca de uma participação social para além da avaliação de impactos da Ciência-Tecnologia na Sociedade: sinalizações de práticas educativas CTS. 2016. 203 p. Tese (Doutorado em Educação) Universidade Federal de Santa Maria, Santa Maria, RS, 2016.

SANTOS, W. L. P. Contextualização no ensino de ciências por meio de temas CTS em uma perspectiva crítica. Ciência e Ensino, v. 01, número especial, 2007. Disponível em: http://prc.ifsp.edu.br/ojs/index.php/cienciaeensino/article/view/149/120. Acesso em: 08 jun. 2019.

SANTOS, W. L. P.; MORTIMER, E. F. Uma análise de pressupostos teóricos da abordagem C-T-S (Ciência - Tecnologia - Sociedade) no contexto da educação brasileira. Ensaio Pesquisa em Educação em Ciências, v. 02, n. 02, p. 01-23, 2000. Disponível em: http://www.portal.fae.ufmg.br/seer/index.php/ensaio/article/view/21/52. Acesso em: 08 jun. 2019.

SANTOS, W.L.P.; SCHNETZLER, R.P. Educação em Química: compromisso com a cidadania. Ijuí: Unijuí, 2003.

SILVA, E.L.; MARCONDES, M.E.R. Materiais didáticos elaborados por professores de química na perspectiva CTS: uma análise das unidades produzidas e das reflexões dos autores. Ciência e Educação, Bauru, v. 21, n. 1, p. 65-83, 2015. Disponível em: http://www.scielo.br/pdf/ciedu/v21n1/1516-7313-ciedu-21-01-0065.pdf Acesso em: 05 jun. 2019.

SOUSA, R.G.; BRITO, L. P. de. Controvérsias em experiências pedagógicas CTS/CTSA na formação inicial de professores de ciências: o que dizem algumas dissertações e teses brasileiras? Amazônia Revista de Educação em Ciências e Matemática, v.12 (23) Jul-Dez 2015. p. 85-102. Disponível em: <http://www.periodicos.ufpa.br/index.php/revistaamazonia/article/view/2015/2764> Acesso em: 20 out. 2019

STRIEDER, R. B. Abordagem CTS na educação científica no Brasil: sentidos e perspectivas. 2012. 283 p. Tese (Doutorado em Ciências). Universidade de São Paulo, São Paulo, 2012. Disponível em: http://www.teses.usp.br/teses/disponiveis/81/81131/tde-13062012-112417/pt-br.php. Acesso em: 08 jul. 2019. 
TRIVELATO, S. L. F. Ciência/Tecnologia/Sociedade: Mudanças Curriculares e Formação de Professores. Tese (Doutorado em Educação). Universidade de São Paulo, São Paulo, 1993.

ZABALA, A. A prática educativa: como ensinar. Porto Alegre: Artes Médicas Sul Ltda., 1998.

ZANON, L.B.; FRISON, M.D.; MALDANER, O. A. Articulação entre produção de currículos e formação inicial de professores de química. IN: ECHEVERRIA, A.R.; ZANON, L.B. Formação superior em química no Brasil. 2010. 